\title{
BACK NUMBERS
}

The present prices of back numbers of the Proceedings are:

\begin{tabular}{ccc} 
Volumes & \multicolumn{1}{c}{ Years } & $£$ per volume \\
$1-30$ & $1844-1934$ & 5.00 \\
$31-50$ & $1935-1954$ & 7.50 \\
$51-60$ & $1955-1964$ & 10.00 \\
$61-64$ & $1965-1968$ & 12.50 \\
$65-70$ & $1969-1971$ & 10.00 \\
$71-$ & $1972-$ & 12.50
\end{tabular}

Orders for back numbers placed during 1975 will be eligible for discount on the following scale

$\begin{array}{cc}\text { Total order } & \begin{array}{c}\text { Rate of } \\ \text { discount }\end{array} \\ £ 26-£ 50 & 5 \% \\ £ 51-£ 100 & 10 \% \\ £ 101-£ 200 & 15 \% \\ \text { above } £ 200 & 25 \%\end{array}$

Orders and enquiries should be addressed to

Mathematical Proceedings

Cambridge Philosophical Society

Bene't Street

Cambridge

England 


\section{Mathematical Proceedings of the Cambridge Philosophical Society}

MPCPCO 78 (Pt 2) $185-356$ (1975) $0305-0041 \quad$ September 1975

CONTENTS

Fröнтон, A. Resolvents and trace form . . . . . . . . . . . $\quad$. 185

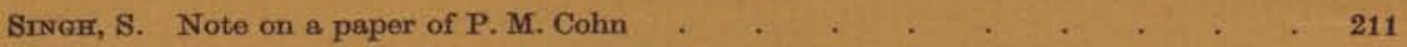

Haztuex, B. and Tomkrnson, M. J. Splitting over nilpotent and hypercentral residuals 215

Coxmrar, H. S. M. Desargues configurations and their collineation groups . . . 227

McMunhes, P. Non-linear angle-sum relations for polyhedral eones and polytopes $\quad 247$

McDiarmid, C. J. H. Rado's theorem for polymatroids $\quad$. . . . . . . . 263

LANGE, H. Moduli spaces of algebraic curves with rational maps . . . . . . $\quad 283$

DevapakkiaM, C. V. Hilbert space methods in the theory of Jordan algebras. I . . 293

WAsseraranN, S. Extension of normal functionals on W*-tensor produets . . . 301

Wrmmex, A. A remark on the K-theory of $B \Gamma_{,}$. . . . . . . . . . 309

EDwards, C. M. On the monotone $\sigma$-envelope of $A(K) \quad$. . . . . . . $\quad . \quad 315$

Connoluy, D. M. and Wrimamson, J. H. A characterization of certain compact sets of measure zero . . . . . . . . . . . . . . . . 317

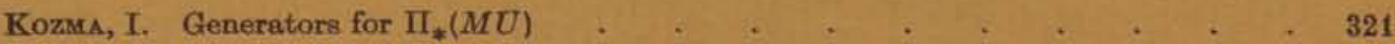

BonLOBAs, B. and VArofounos, N. Th. Representation of systems of measurable sets. 323

MaULdoN, J. G. Extreme points of convex sets of doubly stochastic matrices. II . 327

Goon, I.J. A new formula for cumblants . . . . . . . . . . . $\quad$. 333

Grexy, D. R. Two necessary conditions for embeddability of a Galton-Watson branch-

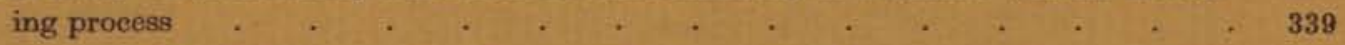

Rawnsuey, J.H. Representations of a semi-direct product by quantization. . . 345

Rosinson, D. C. Applications of variational principles to elassical perturbation theory in general relativity.

\section{CAMBRIDGE UNIVERSITY PRESS}

BENTLIY HOUSE, 200 EUSTON ROAD, LONDON NWI $2 D B$

32 IAST 57 TH STREET, NEW YORK, N.Y.IOO22

Price $£ 4.80$ net (U.S.A. and Canada US $\$ 15.50$ )

Subscription price $£ 12$ per volume ( $£ 24$ per annum) net post free

(US $\$ 38.00$ per volume (US $\$ 76.00$ per annum) in U.S.A. and Canada) 